\title{
Get With The Guidelines Stroke Performance Indicators in a Brazilian Tertiary Hospital
}

\author{
Flavio Augusto de Carvalho ${ }^{a, b}$ Lee H. Schwamm ${ }^{c}$ \\ Gustavo W. Kuster ${ }^{a}$ Monique Bueno Alves ${ }^{a}$ \\ Miguel Cendoroglo Neto ${ }^{a}$ Gisele Sampaio Silva ${ }^{a, b}$ \\ a Programa Integrado de Neurologia, Hospital Israelita Albert Einstein, and b Universidade \\ Federal de São Paulo, UNIFESP, São Paulo, SP, Brazil; ' Department of Neurology, \\ Massachusetts General Hospital, Boston, Mass., USA
}

\section{Key Words}

Get With The Guidelines stroke · Brazil • Performance indicators • Quality of care

\begin{abstract}
Background: Stroke is the fourth leading killer in the US, the first in Brazil and a leading cause of adult long-term disability in both countries. In spite of widespread recommendation, clinical practice guidelines have had limited effect on changing physician behavior. Recognizing that both knowledge and acceptance of guidelines do not necessarily imply guideline adherence, the American Heart Association/American Stroke Association (AHA/ASA) developed a national stroke quality improvement program, the 'Get With The Guidelines (GWTG) stroke'. Even though GWTG has produced remarkable results in the US, other countries have not adopted the program. Methods: We compared the stroke treatment quality indicators from a private Brazilian tertiary hospital to those published by the GWTG stroke program. Seven predefined performance measures selected by the GWTG stroke program as targets for stroke quality improvement were evaluated: (1) tissue plasminogen activator use in patients who arrived $<2 \mathrm{~h}$ from symptom onset; (2) antithrombotic medication use within $48 \mathrm{~h}$ of admission; (3) deep vein thrombosis prophylaxis within $48 \mathrm{~h}$ of admission for nonambulatory patients; (4) discharge use of antithrombotics; (5) discharge use of anticoagulation for atrial fibrillation; (6) dosing of LDL and treatment for LDL $>100 \mathrm{mg} / \mathrm{dl}$ in patients meeting the National Cholesterol Education Program Adult Treatment Panel (NCEP) III guidelines, and (7) counseling for smoking cessation. $\boldsymbol{R} \boldsymbol{e}-$ sults: A total of 343 consecutive patients with acute ischemic stroke $(70.8 \%)$ or transient isch-
\end{abstract}




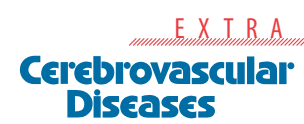

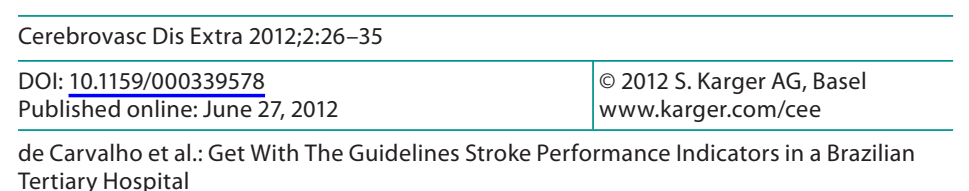

Tertiary Hospital

emic attack (29.2\%) were evaluated from August 2008 to December 2010. Antithrombotic medication within $48 \mathrm{~h}$ was used in $98.5 \%$ of the eligible patients and deep vein thrombosis prophylaxis in $100 \%$. A total of 123 patients arrived within $2 \mathrm{~h}$ from symptoms onset, 23 were eligible for intravenous thrombolysis and 16 were treated (69.5\%). All eligible patients were discharged using antithrombotic medication, and $86.9 \%$ of the eligible patients who had atrial fibrillation received anticoagulation. Only $56.1 \%$ of the eligible patients were treated according to the NCEP III guidelines. Counseling for smoking cessation was done in $63.6 \%$ of the eligible patients. Conclusions: Our study is the first in Brazil and the second outside the US to analyze compliance with the GWTG recommendations. Close attention to a better implementation of these measures may produce an improvement in such results similar to what happened after the full implementation of the program in the US. Whether or not a US disease-based registry such as GWTG can be adopted with success beyond the US is still a matter of debate.

Copyright $\odot 2012$ S. Karger AG, Basel

\section{Introduction}

Stroke is the fourth leading killer in the US, the first in Brazil and a leading cause of adult long-term disability in both countries [1-3]. In spite of widespread recommendation, clinical practice guidelines have had limited effect on changing physician behavior $[4,5]$. Recognizing that both knowledge and acceptance of guidelines do not necessarily implicate in guideline adherence, the American Heart Association/American Stroke Association (AHA/ASA) developed a national stroke quality improvement program, the 'Get With The Guidelines (GWTG) stroke' $[6,7]$. The program was aimed to address the adherence gap by focusing on the redesign of hospital systems of care [7]. A significant improvement in 11 of 13 quality improvement measures in stroke treatment was found after 1 year in hospitals using the GWTG stroke program [8]. It has also led to major and sustained changes in the care of stroke hospitalized patients after a 5-year comparison in a sample of 790 US hospitals [7].

Even though GWTG has produced remarkable results in the US, other countries have not adopted the program. Indeed, the creation of related programs in Brazil and other countries could help to decrease the differences in the quality of stroke treatment delivery among health services both within and among countries. A study carried out in Taiwan is the only report outside the US comparing results from its own stroke registry database with the GWTG data. The report revealed an unsatisfying level of adherence to the proposed GWTG quality measures [9].

We compared the stroke treatment quality indicators from a Joint Commission certified Primary Stroke Center (PSC) in a private Brazilian tertiary hospital to those published by the national GWTG stroke program. Our objective was to gauge the hospital performance and, by consequence, to obtain what would likely be one of the best scenarios in Brazil regarding stroke treatment practices, since the mainstay of a PSC is quality of care and a high level of accomplishment in stroke achievement measures [10,11]. This study sought to reveal room for improvement in our hospital current practices, forming the basis for future implementation of a national-based educational program such as the GWTG.

\section{Patients and Methods}

We evaluated a database of consecutive patients admitted with ischemic stroke or transient ischemic attack (TIA) from August 2008 to December 2010 to the Hospital Israelita Albert Einstein, a private tertiary hospital certified by the Joint Commission International 
as a PSC, with 542 beds at the time of this study, located in São Paulo, Brazil. This database is an ongoing, prospective, institutional initiative created as part of a quality assurance/quality improvement program for stroke treatment. Data collected included demographics, presence of stroke risk factors, National Institutes of Health Stroke Scale (NIHSS) score at admission, in-hospital treatment, modified Rankin scale (mRs) score at discharge, neuroimaging characteristics, and thrombolysis status using a standardized, structured questionnaire. Risk factors were considered if noted on the patient's chart or if medications for known risk factors were used before hospital admission or at discharge [12]. As part of our hospital stroke program, all patients admitted with a diagnosis of ischemic stroke or TIA were identified and followed daily by a case manager nurse.

A research coordinator and a case manager nurse prospectively evaluated medical records from consecutive patients diagnosed with acute ischemic stroke or TIA. TIA was defined as a transient episode of neurological dysfunction caused by focal brain, spinal cord, or retinal ischemia, without acute infarction, with symptoms usually lasting less than $24 \mathrm{~h}$ [13]. Seven predefined performance measures selected by the GWTG stroke program as targets for stroke quality improvement were evaluated: (1) tissue plasminogen activator (rt-PA) use in patients who arrived $<2 \mathrm{~h}$ from symptom onset; (2) antithrombotic medication use within $48 \mathrm{~h}$ of admission; (3) deep vein thrombosis (DVT) prophylaxis within $48 \mathrm{~h}$ of admission for nonambulatory patients; (4) discharge use of antithrombotics; (5) discharge use of anticoagulation for atrial fibrillation (AFib); (6) dosing of LDL and treatment for LDL $>100 \mathrm{mg} / \mathrm{dl}$ in patients meeting National Cholesterol Education Program Adult Treatment Panel (NCEP) III guidelines, and (7) counseling for smoking cessation (table 1). Eligible patients were those without any medical contraindications documented as reasons for nontreatment for each of the applicable measures. Discharge and subacute measures excluded patients who died. The acute rt-PA measures excluded patients with missing time of arrival or treatment times $[7,8]$. A composite measure of performance was computed by summing the numerators for each measure across the patients evaluated to create a composite numerator (all the care that was given), summing the denominators for each measure to form a composite denominator (all the care that should have been given), and reporting the ratio (the percentage of all the needed care that was given). The percentage of adherence to these measures was also obtained for each individual patient through an adherence/eligibility index calculated by the ratio between eligible measures and compliance to them in a single patient. The hospital's Institutional Review Board approved this study.

\section{Statistical Analysis}

Data are reported as mean and standard deviation or median and interquartile range when appropriate. Categorical data were reported as absolute and relative frequency of occurrence. Appropriateness of nonparametric testing was tested after checking normality diagnostics (Kolmogorov-Smirnov tests, Q-Q plots, histograms). Associations between dichotomous patient characteristics and continuous variables were made using the Mann-Whitney U test. Categorical variables were compared with the $\chi^{2}$ test or Fisher's exact test. Multiple logistic regression was used to investigate the influence of epidemiologic and clinical data upon the adherence/eligibility index dichotomized in 85\% of adherence (the GWTG program recognizes hospitals with awards if they follow treatment guidelines in certain key measures in at least $85 \%$ of the patients during the measurement period) [14]. All variables that showed an association in the univariate analysis with a $\mathrm{p}$ value $\leq 0.1$ were included in the multivariate analysis. The limits of statistical significance were set to $5 \%$, and all tests were made using the statistics software MINITAB v16.1. 


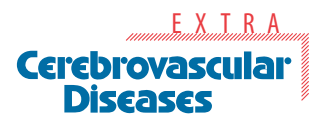

\begin{tabular}{|c|c|}
\hline \multicolumn{2}{|c|}{ Cerebrovasc Dis Extra 2012;2:26-35 } \\
\hline $\begin{array}{l}\text { DOI: } 10.1159 / 000339578 \\
\text { Published online: June 27, } 2012\end{array}$ & $\begin{array}{l}\text { (c) } 2012 \text { S. Karger AG, Basel } \\
\text { www.karger.com/cee }\end{array}$ \\
\hline
\end{tabular}

Table 1. GWTG stroke quality of care measures

\begin{tabular}{|c|c|}
\hline $\begin{array}{l}\text { GWTG stroke quality of } \\
\text { care measure }\end{array}$ & Measure definition for eligible patients* \\
\hline Intravenous rt-PA, $2 \mathrm{~h}$ & $\begin{array}{l}\text { Patients presenting within } 2 \mathrm{~h} \text { of symptom onset who receive i.v. rt-PA } \\
\text { within } 3 \mathrm{~h} \text { of symptom onset }\end{array}$ \\
\hline Early antithrombotics & $\begin{array}{l}\text { Antithrombotic therapy prescribed within } 48 \mathrm{~h} \text { of hospitalization, } \\
\text { including antiplatelet or anticoagulant therapy but not DVT prophylaxis } \\
\text { doses of subcutaneous heparins }\end{array}$ \\
\hline DVT prophylaxis & $\begin{array}{l}\text { Patients at risk for DVT (nonambulatory) who received DVT prophylaxis } \\
\text { by the second hospital day, including warfarin sodium, heparin sodium, } \\
\text { other anticoagulants or pneumatic compression devices }\end{array}$ \\
\hline Antithrombotic medications & Antithrombotic therapy prescribed at discharge \\
\hline $\begin{array}{l}\text { Anticoagulants for patients } \\
\text { with AFib }\end{array}$ & $\begin{array}{l}\text { Anticoagulation therapy prescribed at discharge for patients with AF } \\
\text { documented during the hospitalization, including therapeutic doses of } \\
\text { warfarin, heparin, or other anticoagulant agents }\end{array}$ \\
\hline LDL 100 & $\begin{array}{l}\text { Lipid-lowering agent prescribed at discharge if LDL level is }>100 \mathrm{mg} / \mathrm{dl} \text { or } \\
\text { patient taking lipid-lowering agents on admission }\end{array}$ \\
\hline Smoking & $\begin{array}{l}\text { Smoking cessation intervention (appropriate medication and/or } \\
\text { counseling) provided at discharge }\end{array}$ \\
\hline \multicolumn{2}{|c|}{$\begin{array}{l}\text { Adapted from [8]. } \\
\text { * Eligible patients are those without any medical contraindications documented as reasons for non- } \\
\text { eatment for each of the applicable measures. Discharge and subacute measures exclude patients who } \\
\text { ed. The acute rt-PA measures exclude patients with missing time of arrival, or treatment times. }\end{array}$} \\
\hline
\end{tabular}

\section{Results}

A total of 343 consecutive patients with acute ischemic stroke (70.8\%) or TIA (29.2\%) were evaluated from August 2008 to December 2010. The mean age was $71.1 \pm 14.42$ years; patients were predominantly white (84.4\%) and males (58.7\%). The frequencies of stroke risk factors are shown in table 2 . Acute ischemic stroke with symptoms onset within $12 \mathrm{~h}$ prior to hospital admission accounted for $74.7 \%$ of the stroke admissions. The median NIHSS at admission was 3 [8]. The majority of the patients (79.9\%) were followed by a neurologist during their in-hospital treatment.

\section{Stroke Achievement Measures}

A total of 123 patients arrived within $2 \mathrm{~h}$ from symptoms onset, 23 were eligible for intravenous thrombolysis, and 16 were treated (69.5\%). Antithrombotic medication within $48 \mathrm{~h}$ was used in $98.2 \%$ of the eligible patients, and DVT prophylaxis in $100 \%$. All eligible patients were discharged using antithrombotic medication and $86.7 \%$ of the eligible patients who had AFib received anticoagulation. Lipid levels were tested in only $35.6 \%$ of the patients, and LDL levels $\geq 100 \mathrm{mg} / \mathrm{dl}$ were found in $19.5 \%$ of the patients. Only $56.1 \%$ of eligible patients were treated according to the NCEP guidelines. Counseling for smoking cessation was done in $66.6 \%$ of the eligible patients (table 3). Patients with concomitant hypertension or diabetes and those presenting with an ischemic stroke instead of a TIA were more frequently investigated and treated for dyslipidemia when appropriate (table 4). Patients followed by 


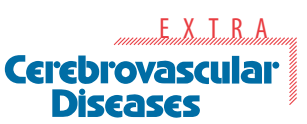

Table 2. Clinical characteristics of the 343 consecutive patients evaluated

\begin{tabular}{|c|c|}
\hline \multicolumn{2}{|l|}{ Cerebrovasc Dis Extra 2012;2:26-35 } \\
\hline $\begin{array}{l}\text { DOI: } 10.1159 / 000339578 \\
\text { Published online: June } 27,2012\end{array}$ & $\begin{array}{l}\text { @ } 2012 \text { S. Karger AG, Basel } \\
\text { www.karger.com/cee }\end{array}$ \\
\hline \multicolumn{2}{|c|}{$\begin{array}{l}\text { de Carvalho et al.: Get With The Guidelines Stroke Performance Indicators in a Braziliar } \\
\text { Tertiary Hospital }\end{array}$} \\
\hline \multicolumn{2}{|l|}{ Characteristic $(\mathrm{n}=343)$} \\
\hline Male & $58.7 \%$ \\
\hline White & $84.4 \%$ \\
\hline Black or Afro descendant & $3.8 \%$ \\
\hline Mean age $\pm S D$, years & $71.1 \pm 14.4$ \\
\hline Hypertension & $59.7 \%$ \\
\hline Diabetes mellitus & $33.7 \%$ \\
\hline Dyslipidemia & $28.8 \%$ \\
\hline Smoking prior to 1 st month & $13.4 \%$ \\
\hline Atrial fibrillation & $18.9 \%$ \\
\hline Prior stroke & $26.5 \%$ \\
\hline Coronary artery disease & $17.9 \%$ \\
\hline Current stroke & $70.8 \%$ \\
\hline Current transient ischemic attack & $29.2 \%$ \\
\hline
\end{tabular}

Risk factors were considered if noted on the patient's chart or if medications for known risk factors were used before hospital admission or at discharge.

a neurologist during hospital admission were more frequently anticoagulated for AFib than those followed by non-neurologists ( 80.7 vs. $54.5 \%, \mathrm{p}=0.03$ ) (table 5).

The composite measure score was $84.7 \%$. Hypertension $(\mathrm{p}=0.04)$, dyslipidemia $(\mathrm{p}<$ $0.01)$, and a lower $\mathrm{mRs}$ at discharge $(\mathrm{p}<0.01)$ were found to be associated with an adherence/ eligibility index of $85 \%$ or higher in the univariate analyses. After multivariate adjustment, only dyslipidemia [OR $3.52(2.05-6.05)$ ] and a lower mRs [OR $0.84(0.74-0.96$ ] at discharge remained in the model as predictors of higher adherence/eligibility index (fig. 1).

\section{Discussion}

We described the stroke treatment quality indicators from a Brazilian tertiary care private hospital and compared them to those obtained by the GWTG stroke program in the US. Overall, we found adherence rates similar to the GWTG stroke program for i.v.-rt-PA use, early use of antithrombotics, DVT prophylaxis and prescription of antithrombotics at discharge. Our adherence rates to smoking cessation counseling, anticoagulation at discharge for patients with AFib and lipid lowering treatment were lower than those reported by the GWTG stroke program. Interestingly, in the GWTG cohort, compliance with these three measures also showed the lowest compliance in the baseline year and had major improvement after 5 years [7].

In São Paulo, around 1 million people have potential access to Albert Einstein (a private hospital). In the Albert Einstein neighborhood, there are a total of 923 hospital beds that could potentially treat strokes. Therefore, nearby hospitals may be admitting fewer early arriving patients due to preferential emergency medical services triage or insurance coverage, explaining the high frequency of early arrivals observed in our series. Our stroke team consists of board-certified neurologists trained in acute stroke care in house $24 \mathrm{~h}$ per day, 7 days a week. The hospital has a written protocol available for acute stroke care, a dedicated interventional neuroradiologist team available around the clock, advanced neuroimaging capability, including computerized tomography (CT), CT angiography, CT perfusion, with the 
Table 3. Comparison of the seven achievement measures data from the GWTG national database to our single institution database

\begin{tabular}{llll}
\hline Performance measures & $\begin{array}{l}\text { GWTG baseline } \\
\text { data (2003) }\end{array}$ & $\begin{array}{l}\text { GWTG } \\
\text { data set (2007) }\end{array}$ & $\begin{array}{l}\text { Our database } \\
(2008-2010)\end{array}$ \\
\hline $\begin{array}{l}\text { Acute interventions } \\
\quad \text { i.v. tPA for 2 h }\end{array}$ & $42.1 \%$ & $72.8 \%$ & $69.5 \%$ \\
$\quad$ Early antithrombotics & $91.5 \%$ & $97.0 \%$ & $98.2 \%$ \\
$\quad \begin{array}{l}\text { DVT prophylaxis } \\
\text { Discharge interventions }\end{array}$ & $73.8 \%$ & $89.5 \%$ & $100 \%$ \\
$\quad$ Smoking cessation & $65.2 \%$ & $93.6 \%$ & $66.6 \%$ \\
$\quad$ Anticoagulation for AFib & $95.0 \%$ & $98.4 \%$ & $86.7 \%$ \\
$\quad$ Discharge antithrombotics & $95.7 \%$ & $98.9 \%$ & $100 \%$ \\
$\quad$ Lipid-lowering drug for LDL-c $100 \mathrm{mg} / \mathrm{dl}^{*}$ & $73.6 \%$ & $88.3 \%$ & $56.1 \%$ \\
\hline
\end{tabular}

LDL-c $=$ Low-density lipoprotein cholesterol. ${ }^{*}$ Not dosed.

Table 4. Characteristics of patients who received or who did not receive lipid lowering treatment when eligible
Table 5. Characteristics of patients who received or who did not receive anticoagulation for AFib when eligible

\begin{tabular}{lllr}
\hline $\begin{array}{l}\text { Compliance with lipid } \\
\text { lowering recommendation }\end{array}$ & Yes & No & $\mathrm{p}$ \\
\hline Mean age \pm SD, years & $71.9 \pm 12.9$ & $69.2 \pm 17.4$ & 0.16 \\
Female gender & $39.9 \%$ & $44.8 \%$ & 0.40 \\
Hypertension & $65.5 \%$ & $47.6 \%$ & $<0.01$ \\
Diabetes mellitus & $39.1 \%$ & $21.9 \%$ & $<0.01$ \\
Coronary artery disease & $19.3 \%$ & $15.2 \%$ & 0.36 \\
AFib & $18.9 \%$ & $19.0 \%$ & 0.98 \\
Previous stroke & $26.9 \%$ & $25.7 \%$ & 0.82 \\
Previous TIA & $4.2 \%$ & $1.0 \%$ & 0.11 \\
TIA at presentation & $26.5 \%$ & $37.1 \%$ & 0.04 \\
Smoking & $13.4 \%$ & $13.3 \%$ & 0.97 \\
Followed by a neurologist & $81.5 \%$ & $76.2 \%$ & 0.25 \\
\hline
\end{tabular}

\begin{tabular}{llcl}
\hline $\begin{array}{l}\text { Anticoagulation for AFib } \\
\text { when indicated }\end{array}$ & Yes & No & $\mathrm{p}$ \\
\hline Mean age \pm SD, years & $70.9 \pm 14.4$ & $75.73 \pm 14.4$ & 0.27 \\
Female gender & $42.2 \%$ & $18.2 \%$ & 0.11 \\
Hypertension & $59.6 \%$ & $72.7 \%$ & 0.38 \\
Diabetes mellitus & $33.4 \%$ & $45.5 \%$ & 0.40 \\
Coronary artery disease & $18.4 \%$ & $9.1 \%$ & 0.43 \\
Dyslipidemia & $28.6 \%$ & $36.4 \%$ & 0.57 \\
Previous stroke & $27.1 \%$ & $9.1 \%$ & 0.18 \\
Previous TIA & $3.3 \%$ & 0 & 0.53 \\
TIA at presentation & $29.8 \%$ & $27.3 \%$ & 0.85 \\
Smoking & $13.6 \%$ & $9.1 \%$ & 0.66 \\
Followed by a neurologist & $80.7 \%$ & $54.5 \%$ & 0.03 \\
\hline
\end{tabular}




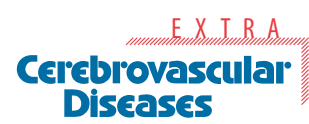

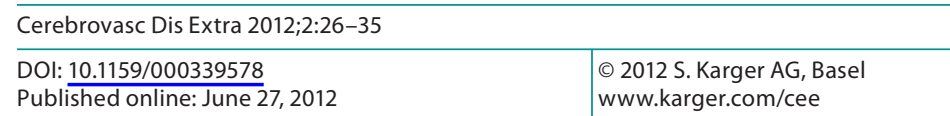

www.karger.com/cee

de Carvalho et al.: Get With The Guidelines Stroke Performance Indicators in a Brazilian Tertiary Hospital
Fig. 1. Factors associated with compliance to the adherence/eligibility index on a multivariate logistic regression model.

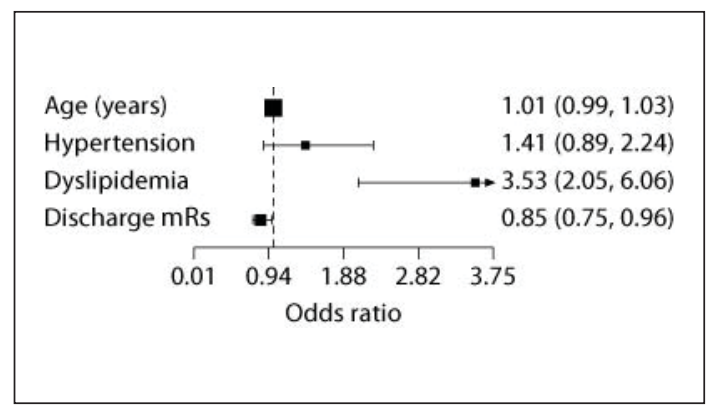

CT scanner located at the emergency department, and acute magnetic resonance imaging (MRI), and a critical care unit with eight beds dedicated to neurologic and neurosurgical patients. All neurologists are certified to perform the NIHSS and undergo periodic training program and protocol review. Our program is the only Latin American stroke service certified as a PSC by the Joint Commission International. Therefore, it is expected that the findings from our study likely reflect best performance in acute stroke treatment, and national performance data would likely be less compliant.

In the acute phase, all patients were followed by the stroke team. However, after the acute phase, our patients were admitted to a physician of their choice, who was frequently not part of the stroke team. This might in part explain why our performance measures were better in the acute phase (thrombolysis rate, use of antiplatelets in the first $48 \mathrm{~h}$ ) than at discharge (use of lipid lowering agents, smoking cessation counseling, and anticoagulation for AFib). The open versus closed model has been discussed extensively in the intensive care unit (ICU) literature, with findings suggesting improved outcomes in terms of mortality and morbidity when ICUs adopt a closed management model $[15,16]$. In a closed ICU system, intensivists are the admitting physicians and deliver around-the-clock coverage through suitably trained physician staff [17]. This model seems to be beneficial due to its ability to provide complete care by a critical care-trained physician who is able to put all patient information into the context of their current critical illness. In the stroke literature, systematic reviews and randomized trials have shown that provision of care in a closed stroke unit can amplify the number of patients who survive, return home, and recover independence in daily activities [18-20].

Quality improvement in stroke treatment has been the focus of the AHA/ASA attention for almost a decade now, when the GWTG stroke program was launched [5]. Since then, several studies reported optimistic data that revealed a remarkable improvement in stroke treatment in institutions under the influence of this program [7, 8]. For instance, i.v. rt-PA rates in eligible patients admitted in the first $2 \mathrm{~h}$ after stroke went from 42.1 to $72.8 \%$ after 5 years, and smoking cessation counseling was offered for $96.1 \%$ of patients after 5 years, in comparison to a modest rate of $65.2 \%$ in the first year [7]. If adherence to as many possible measures is analyzed through a composite score, our institution achieved $84.7 \%$ of compliance with all possible measures. This result is very close to the composite score of performed interventions divided by possible interventions that was reported by the GWTG program in its baseline year and higher than the composite score reported in Taiwan [7, 9]. The American program started with an average of $83.5 \%$ of adherence to all possible measures jumping to 93.9\% after 5 years [7].

In our series, the presence of certain risk factors in a patient, such as hypertension and dyslipidemia, might have triggered the clinician to be more attentive to the treatment measures, as they were correlated with better adherence/eligibility index values. Also lower mRs 
scores at discharge was an independent predictor of a higher adherence/eligibility index. There are two possible explanations for this finding: physicians might be more concerned with the treatment of patients with a more favorable functional outcome at discharge and therefore be more compliant with treatment measures, or adherence to simple measures might have had a favorable impact upon functional outcome.

We had worse lipid testing rates when compared to hospitals from the GWTG program in their baseline year of analysis. In GWTG hospitals, frequency of LDL measurement went from 54.3 to $81.9 \%$ after a 5 -year period [21]. Our frequency stands lower than that observed initially in GWTG hospitals, with only $35.6 \%$ of our patients having LDL-cholesterol dosed. Some determinants for such low lipid testing rates in the US were found to be gender-related (lower in women) and risk factor-related (less tested in nonsmokers, those with AFib, those with a history of stroke or TIA, and those with TIA) [21]. In our series, patients with TIA were also less frequently tested and treated for dyslipidemia than patients with ischemic stroke. The other characteristics found to be related to adherence to the lipid lowering in the US (gender, smoking status, AFib, previous stroke or TIA) were not related to the adherence to the lipid lowering treatment quality indicator in our series.

The rate of anticoagulation for eligible patients with AFib in our series was lower than in GWTG hospitals but higher than that reported in other developing countries [7, 22]. Independent predictors for secondary stroke prevention with anticoagulation in patients with AFib in a large US series were younger age, male sex, independent activities of daily life function before the stroke, being discharged to home, being fully conscious on admission, and health care region [23]. In our series, there could be a physician-related factor to explain in part the lower than expected rates of anticoagulation for patients with AFib, as not all patients were treated by a neurologist after the acute phase $(80.7 \%$ of the eligible patients followed by a neurologist were anticoagulated for AFib vs. $54.5 \%$ of the patients followed by other physicians, $\mathrm{p}=0.03$ ).

Our study has some limitations. We report data from a single center, with a relatively small sample size of predominantly white patients and no concurrent controls. Quality indicators from hospitals in Brazil other than our primary stroke center remain to be analyzed in order to assess the real influence of GWTG recommendations in a country highly influenced by the ASA practice guidelines.

Our study is the first in Brazil and the second outside the US to analyze compliance with the GWTG recommendations. Close attention to a better implementation of these measures may produce an improvement in such results similar to what happened after the full implementation of the program in the US. Whether or not a US disease-based registry such as GWTG can be adopted with success beyond the US is still a matter of debate. Cultural, political and even formulary or language differences may be barriers to the broader adoption and application of registries such as GWTG stroke around the world [24]. It could be challenging for countries with lower health care expenditures to follow all of the GWTG stroke recommendations, some of which can be costly to implement. Whether our results could be further improved by the implementation of a national stroke quality improvement program designed specifically for Brazil or Latin America remains to be evaluated. 


\section{References}

de Carvalho et al.: Get With The Guidelines Stroke Performance Indicators in a Brazilian Tertiary Hospital

-1 Roger VL, Go AS, Lloyd-Jones DM, Benjamin EJ, Berry JD, Borden WB, Bravata DM, Dai S, Ford ES, Fox CS, Fullerton HJ, Gillespie C, Hailpern SM, Heit JA, Howard VJ, Kissela BM, Kittner SJ, Lackland DT, Lichtman JH, Lisabeth LD, Makuc DM, Marcus GM, Marelli A, Matchar DB, Moy CS, Mozaffarian D, Mussolino ME, Nichol G, Paynter NP, Soliman EZ, Sorlie PD, Sotoodehnia N, Turan TN, Virani SS, Wong ND, Woo D, Turner MB: Heart disease and stroke statistics - 2012 update: A report from the American Heart Association. Circulation 2012;125:e2-e220.

-2 de Padua Mansur A, de Fatima Marinho do Souza M, Favarato D, Avakian SD, Machado Cesar LA, Mendes Aldrigui J, Franchini Ramires JA: Stroke and ischemic heart disease mortality trends in Brazil from 1979 to 1996. Neuroepidemiology 2003;22:179-183.

-3 Lotufo PA, De Lolio CA: Trends of mortality from cerebrovascular disease in the state of São Paulo: 1970 to 1989 (article in Portuguese). Arq Neuropsiquiatr 1993;51:441-446.

-4 Cabana MD, Rand CS, Powe NR, Wu AW, Wilson MH, Abboud PA, Rubin HR: Why don't physicians follow clinical practice guidelines? A framework for improvement. JAMA 1999;282:1458-1465.

- 5 Davis D, O'Brien MA, Freemantle N, Wolf FM, Mazmanian P, Taylor-Vaisey A: Impact of formal continuing medical education: do conferences, workshops, rounds, and other traditional continuing education activities change physician behavior or health care outcomes? JAMA 1999;282:867-874.

6 Get With The Guidelines ${ }^{\circledR}$-Stroke Home Page. Available at: http://www.heart.org/HEARTORG/ HealthcareResearch/GetWithTheGuidelinesHFStroke/Get-With TheGuidelineHFStroke_UCM_ 001099_SubHomePage.jsp (accessed December 19, 2011).

-7 Schwamm LH, Fonarow GC, Reeves MJ, Pan W, Frankel MR, Smith EE, Ellrodt G, Cannon CP, Liang L, Peterson E, LaBresh KA: Get With The Guidelines-Stroke is associated with sustained improvement in care for patients hospitalized with acute stroke or transient ischemic attack. Circulation 2009;119:107-115.

-8 LaBresh KA, Reeves MJ, Frankel MR, Albright D, Schwamm LH: Hospital treatment of patients with ischemic stroke or transient ischemic attack using the 'Get With The Guidelines' program. Arch Intern Med 2008;168:411-417.

-9 Hsieh FI, Lien LM, Chen ST, Bai CH, Sun MC, Tseng HP, Chen YW, Chen CH, Jeng JS, Tsai SY, Lin HJ, Liu CH, Lo YK, Chen HJ, Chiu HC, Lai ML, Lin RT, Sun MH, Yip BS, Chiou HY, Hsu CY: Get With The Guidelines-Stroke performance indicators: surveillance of stroke care in the Taiwan stroke registry: Get With The Guidelines-stroke in Taiwan. Circulation 2010;122:1116-1123.

-10 Alberts MJ, Hademenos G, Latchaw RE, Jagoda A, Marler JR, Mayberg MR, Starke RD, Todd HW, Viste KM, Girgus M, Shephard T, Emr M, Shwayder P, Walker MD: Recommendations for the establishment of primary stroke centers. Brain attack coalition. JAMA 2000;283:3102-3109.

- 11 Alberts MJ, Latchaw RE, Jagoda A, Wechsler LR, Crocco T, George MG, Connolly ES, Mancini B, Prudhomme S, Gress D, Jensen ME, Bass R, Ruff R, Foell K, Armonda RA, Emr M, Warren M, Baranski J, Walker MD: Revised and updated recommendations for the establishment of primary stroke centers: a summary statement from the brain attack coalition. Stroke 2011;42:2651-2665.

-12 van Swieten JC, Koudstaal PJ, Visser MC, Schouten HJ, van Gijn J: Interobserver agreement for the assessment of handicap in stroke patients. Stroke 1988;19:604-607.

-13 Easton JD, Saver JL, Albers GW, Alberts MJ, Chaturvedi S, Feldmann E, Hatsukami TS, Higashida RT, Johnston SC, Kidwell CS, Lutsep HL, Miller E, Sacco RL: Definition and evaluation of transient ischemic attack: a scientific statement for healthcare professionals from the American Heart Association/American Stroke Association Stroke Council; Council on Cardiovascular Surgery and Anesthesia; Council on Cardiovascular Radiology and Intervention; Council on Cardiovascular Nursing; and the Interdisciplinary Council on Peripheral Vascular Disease. The American Academy of Neurology affirms the value of this statement as an educational tool for neurologists. Stroke 2009;40: 2276-2293.

14 Get With The Guidelines ${ }^{\circledR}$-Stroke Home Page. Available at: http://www.heart.org/HEARTORG/ HealthcareResearch/GetWithTheGuidelinesHFStroke/GetWithTheGuidelinesStrokeHomePage/ Get-With-The-Guidelines-Stroke-RecognitionCriteria_UCM_310337_Article.jsp (accessed June 18, 2012)

-15 Pollack MM, Katz RW, Ruttimann UE, Getson PR: Improving the outcome and efficiency of intensive care: the impact of an intensivist. Crit Care Med 1988;16:11-17. 
-16 Brown JJ, Sullivan G: Effect on ICU mortality of a full-time critical care specialist. Chest 1989;96: $127-129$.

-17 Multz AS, Chalfin DB, Samson IM, Dantzker DR, Fein AM, Steinberg HN, Niederman MS, Scharf SM: A 'closed' medical intensive care unit (MICU) improves resource utilization when compared with an 'open' MICU. Am J Respir Crit Care Med 1998;157:1468-1473.

-18 How do stroke units improve patient outcomes? A collaborative systematic review of the randomized trials. Stroke unit trialists collaboration. Stroke 1997;28:2139-2144.

19 Langhorne P, Dennis MS: Stroke units: the next 10 years. Lancet 2004;363:834-835.

-20 Langhorne P, de Villiers L, Pandian JD: Applicability of stroke-unit care to low-income and middleincome countries. Lancet Neurol 2012;11:341-348.

-21 Smith EE, Pan W, Olson D, Reeves MJ, Ovbiagele B, Peterson ED, Fonarow GC, Schwamm LH: Frequency and determinants of lipid testing in ischemic stroke and transient ischemic attack: findings from Get With the Guidelines-Stroke. Stroke 2010;41:232-238.

-22 Lin S, Wu B, Hao ZL, Kong FY, Tao WD, Wang DR, He S, Liu M: Characteristics, treatment and outcome of ischemic stroke with atrial fibrillation in a Chinese hospital-based stroke study. Cerebrovasc Dis 2011;31:419-426.

-23 Glader EL, Stegmayr B, Norrving B, Terent A, Hulter-Asberg K, Wester PO, Asplund K: Large variations in the use of oral anticoagulants in stroke patients with atrial fibrillation: a Swedish national perspective. J Intern Med 2004;255:22-32.

-24 Horgan F, McGee H, Hickey A, Whitford DL, Murphy S, Royston M, Cowman S, Shelley E, Conroy RM, Wiley M, O'Neill D: From prevention to nursing home care: a comprehensive national audit of stroke care. Cerebrovasc Dis 2011;32:385-392. 